\title{
Pengaruh Pendidikan, Pengalaman Kerja dan Motivasi Kerja Terhadap Kinerja Karyawan Pada Hotel Champlung Mas Resort \& Spa Legian
}

\author{
Ni Luh Metri Lestari dan A.A Media Martadiani \\ Progam Studi Manajemen, Fakultas Ekonomi dan Bisnis, Universitas Warmadewa Denpasar, Bali-Indonesia \\ metrilestari@gmail.com
}

\section{How to cite (in APA style):}

Lestari, N. L. M., \& Martadiani, A. A. M. (2021). Pengaruh Pendidikan, Pengalaman Kerja dan Motivasi Kerja Terhadap Kinerja Karyawan Pada Hotel Champlung Mas Resort \& Spa Legian. Wacana Ekonomi (Jurnal Ekonomi, Bisnis dan Akuntansi). 20 (1), pp.72-76. https://doi.org/10.22225/we.20.1.3151.72-76

\begin{abstract}
In an effort to improve employee performance, high work experience education and work motivation are expected to be able to improve the quality of service to guests. The purpose of this study was to determine and analyze the effect of education, work experience and work motivation on employee performance at Hotel Champlung Mas Resort \& Spa Legian. In this study, the employees used as a sample were 52 people. The data analysis technique consisted of validity test, reliability test, classical assumption test, multiple linear regression analysis, $F$ test, and $t$ test. The results of the analysis show that the effect of education on employee performance is obtained tcount (3.949) $>$ ttable (2.010) with a significance level of $0.000<i 0.05$, which means that the education variable has a significant positive effect on employee performance at Hotel Champlung Mas Resort \& Spa Legian. The effect of work experience on employee performance is obtained tcount (2.271)>t table (2.010) with a significance level of $0.028<0.05$, which means that the work experience variable has a significant positive effect on employee performance at Hotel Champlung Mas Resort \& Spa Legian. The influence of work motivation on employee performance is obtained tcount (4.026)> ttable (2.010) with a significance level of $0.000<0.05$, which means that the work motivation variable has a significant positive effect on employee performance at Hotel Champlung Mas Resort \& Spa Legian. Based on the F test (simultaneously) obtained Fcount (17.384)> Ftable (2.79) with a significance value of $F$ is $0.000<0.05$. This means that the variables education, work experience and work motivation simultaneously have a significant effect on employee performance at Hotel Champlung Mas Resort \& Spa Legian with a value of R2 $=52.1 \%$ which means that $52.1 \%$ of employee performance at Hotel Champlung Mas Resort. \& Spa Legian is influenced by the variables of education, work experience and work motivation while the remaining $47.9 \%$ is influenced by other variables not examined in this study.
\end{abstract}

Keywords: Education; Work Experience; Work Motivation; Employee Performance

\begin{abstract}
Abstrak
Dalam usaha meningkatkan kinerja karyawan, tingginya pendidikan pengalaman kerja dan motivasi kerja tersebut diharapkan mampu meningkatkan kualitas pelayanan terhadap tamu. Tujuan penelitian ini adalah untuk mengetahui dan menganalisis pengaruh pendidikan, pengalaman kerja dan motivasi kerja terhadap kinerja karyawan pada Hotel Champlung Mas Resort \& Spa Legian. Pada penelitian ini karyawan yang digunakan sebagai sampel sebanyak 52 orang. Teknik analisis data terdiri dari uji validitas, uji reliabilitas, uji asumsi klasik, analisis regresi linier berganda, uji F, dan uji t. Hasil analisis menunjukkan bahwa pengaruh pendidikan terhadap kinerja karyawan diperoleh thitung $(3,949)>$ ttabel $(2,010)$ dengan tingkat signifikansi $0,000<0,05$ yang berarti bahwa variabel pendidikan berpengaruh positif signifikan terhadap kinerja karyawan pada Hotel Champlung Mas Resort \& Spa Legian. Pengaruh pengalaman kerja terhadap kinerja karyawan diperoleh thitung $(2,271)>\mathrm{t}$ tabel $(2,010)$ dengan tingkat signifikansi $0,028<0,05$ yang berarti bahwa variabel pengalaman kerja berpengaruh positif signifikan terhadap kinerja karyawan pada Hotel Champlung Mas Resort \& Spa Legian. Pengaruh motivasi kerja terhadap kinerja karyawan diperoleh thitung $(4,026)>$ ttabel $(2,010)$ dengan tingkat signifikansi $0,000<0,05$ yang berarti bahwa variabel motivasi kerja berpengaruh positif signfikan terhadap kinerja karyawan pada Hotel Champlung Mas Resort \& Spa Legian. Berdasarkan uji F (secara isimultan) diperoleh Fhitung $(17,384)>$ Ftabel $(2,79)$ dengan nilai signifikansi $\mathrm{F}$ adalah $0,000<0,05$. Hal ini berarti bahwa variabel pendidikan, pengalaman kerja dan motivasi kerja secara simultan berpengaruh signifikan terhadap kinerja karyawan pada Hotel Champlung Mas Resort \& Spa Legian dengan nilai R2 = $52,1 \%$ yang berarti bahwa sebesar 52,1\% kinerja karyawan pada Hotel Champlung Mas Resort \& Spa Legian dipengaruhi oleh variabel pendidikan, pengalaman kerja dan motivasi kerja sedangkan sisanya sebesar $47,9 \%$ dipengaruhi oleh variabel lain yang tidak diteliti pada penelitian ini.
\end{abstract}


Kata Kunci: Pendidikan; Pengalaman Kerja; Motivasi Kerja; Kinerja Karyawan

\section{PENDAHULUAN}

Pariwisata merupakan salah satu sektor yang paling berkembang di pulau Bali, karena Bali merupakan salah satu tujuan wisata di idunia. Perkembangan pariwisata yang begitu pesat menuntut suatu daerah tujuan wisata untuk menyediakan sarana dan prasarana di daerah tersebut. Salah satunya adalah hotel. Hotel merupakan salah satu sarana untuk menunjang perkembangan pariwisata guna memenuhi kebutuhan akomodasi bagi wisatawan yang sedang berlibur. Begitu iuga di pulau Bali, perkembangan hotel berjalan sangat cepat untuk menunjang sarana dan prasarana kepariwisataan yang di butuhkan oleh wisatawan yang berkunjung ke Bali antara lain sarana akomodasi, makanan dan minuman.

Kebutuhan yang saat ini begitu kompleks dari hal yang paling pokok/primer terutama kebutuhan sandang, pangan, pendidikan, istirahat kerja yang cukup, perlu mendapatkan skala prioritas utama dalam hal pemenuhannya. Selain itu, pemenuhan kebutuhan dari para pegawai akan pelayanan dan penghargaan oleh atasan terhadap kinerja yang dihasilkannya yang sesuai dengan prinsip keadilan dapat memotivasi kerja mereka.

Pengalaman kerja merupakan penguasaan pengetahuan dan keterampilan karyawan yang diukur dari lama masa kerja, tingkat pengetahuan dan keterampilan yang dimiliki karyawan. Pengalaman hanya bisa didapatkan melalui tempat kerja. Dapat disimpulkan bahwa pengalaman kerja yang memadai akan membantu karyawan dalam menyelesaikan pekerjaan. Pengalaman kerja yang baik memberikan keahlian dan keterampilan kerja berdasarkan pada jangka waktu dalam menjalani pekerjaan tersebut (Handoko, 2014).

Motivasi merupakan dorongan, keinginan, hasrat dan tenaga penggerak yang berasal dari diri manusia untuk berbuat atau melakukan sesuatu. Jadi, pada dasarnya apabila perusahaan ingin meraih kinerja yang optimal sesuai dengan target yang telah ditentukan maka perusahaan haruslah memberikan motivasi pada karyawan agar karyawan mau dan rela mencurahkan tenaga dan pikiran yang dimiliki demi pekerjaan.

Kinerja karyawan pada umumnya diartikan sebagai kesuksesan seseorang dalam melaksanakan suatu pekerjaan. Kinerja karyawan merupakan hasil kerja yang dicapai seseorang dalam melaksanakan tugas-tugas yang dibebankan kepadanya untuk mencapai target kerja. Ada beberapa alasan kenapa perusahaan mensyaratkan pentingnya pengalaman, dengan pengalaman tersebut maka perusahaan tidak perlu lagi melaksanakan training dengan pertimbangan pengenalan terhadap pekerjaanya saat ini, selain itu dengan perusahaan menerima seorang karyawan yang berpengalaman dengan maksud agar karyawan itu mempunyai atau menemukan ide-ide baru dalam memecahkan masalah yang pernah timbul sebelumnya dan motivasi kerja berpengaruh terhadap kinerja kerja karyawan pada dasarnya apabila perusahaan ingin meraih kinerja yang optimal sesuai dengan target yang telah ditentukan maka perusahaan haruslah memberikan motivasi pada karyawan agar karyawan mau dan rela mencurahkan tenaga dan pikiran yang dimiliki demi pekerjaan.

\section{TINJAUAN PUSTAKA}

\section{Pendidikan}

Pendidikan merupakan upaya membekali peserta didik demi kelangsungan masa depannya. Pendidikan adalah pembekalan pengetahuan dan keterampilan kepada seseorang agar mempunyai keterampilan dan minat (Syaifudin \& Sagoro, 2017).

\section{Pengalaman Kerja}

Pengalaman kerja merupakan kegiatan melakukan segala sesuatu yang pernah dialami oleh seseorang, dengan adanya pengalaman yang kita dapat, maka kita dalam bekerja tidak ada hambatan. Jika kalau kita dalam bekerja belum ada pengalaman maka dalam bekerja di suatu perusahaan apapun kita akan mengalami kesulitan, karena kita tidak tahu langkah apa yang selanjutnya akan kita kerjakan (Sendjaja, 2004). 


\section{Motivasi Kerja}

Motivasi adalah perilaku dan faktor-faktor yang mempengaruhi pegawai untuk berperilaku terhadap pekerjaannya. Motivasi kerja merupakan proses yang menunjukan intensitas individu, arah dan ketentuan sebagai upaya mencapai tujuan organisasi (Priansa, 2016).

\section{Kinerja Karyawan}

Kinerja (Performance) adalah hasil kerja yang dapat dicapai oleh seseorang atau sekelompok orang dalam suatu perusahaan, sesuai dengan wewenang dan tanggung jawab masing-masing, dalam rangka upaya mencapai tujuan organisasi bersangkutan secara legal, tidak melanggar hukum dan sesuai dengan moral maupun etika (Prawirosentono \& Primasari, 2017).

\section{METODE}

Penelitian ini dilakukan pada Hotel Champlung Mas Resort \& Spa Legian yang terletak di Jln. Lebak bene Legian Kuta Badung. Populasi dalam penelitian ini adalah seluruh karyawan pada Hotel Champlung Mas Resort \& Spa yaitu sebanyak 109 orang, serta sampel 52 responden menggunakan rumus slovin. Penelitian ini menggunakan data kualitatif dan data kuantitatif. Teknik analisis data yang digunakan pada penelitian ini adalah mengguunakan regresi linier berganda, dalam perhitungannya menggunakan software dengan progam SPSS version 20 for Windows.

\section{HASIL DAN PEMBAHASAN}

Data dalam penelitian ini diperoleh dari 52 responden melalui penyebaran kuesioner. Pemaparan berikut ini meliputi empat kriteria responden yaitu berdasarkan jenis kelamin, usia, dan tingkat pendidikan. Dalam penelitian ini sebagian besar responden berjenis kelamin laki-laki dengan presentase sebesar 51,92\%. Jika di lihat dari usia, yang memiliki usia 25-34 tahun mendominasi dengan presentase sebesar $32,69 \%$. Jika dilihat dari tingkat pendidikan, yang memiliki tingkat pendidikan terakhir SLTA yang mendominasi dengan persentase sebesar 51,92\%.

Berdasarkan hasil uji instrument dengan penyebaran kuesioner pada 52 responden, seluruh indikator variabel pada penelitian ini yaitu pendidikan, pengalaman kerja, motivasi kerja dan kinerja karyawan valid karena memiliki nilai koefisien korelasi lebih dari 0,30. Begitu juga dengan hasil uji reliable, instrument dalam penelitian variabel-variabel penelitian dikatakan reliable karena masingmasing variabel memiliki nilai Alpha lebih besar 0,60.

Berdasarkan uji normalitas, nilai Asdymp. Sig. (2-tailed) yaitu sebesar 0,256 yaitu lebih besar dari 0,05 yang menunjukan bahwa data terdistribusi secara normal. Berdasarkan uji multikolineritas ditunjukkan bahwa seluruh variabel bebas memiliki nilai tolerance $>0,10$, begitu juga dengan hasil perhitungan nilai VIF, seluruh variabel memiliki nilai VIF $<10$. Hal ini berarti bahwa pada model regresi yang dibuat tidak terdapat gejala multikolinearitas. Berdasarkan uji heterokedastisitas bahwa masing-masing model memiliki nilai signifikansi lebih besar dari 0,05. Berarti di dalam model regresi ini tidak terjadi kesamaan varian dari residual satu pengamatann ke pengamatan lainnya atau tidak terjadi heteroskedastisitas.

Pengujian data dalam penelitian ini menggunakan teknik regresi linier berganda diolah dengan software Statistical Packagge for Social Sciences (SPSS) Pengaruh pendidikan, pengalaman kerja, motivasi kerja terhadap kinerja karyawan valid dapat dianalisis menggunakan perhitungan regresi linier berganda. 
Wacana Ekonomi (Jurnal Ekonomi Bisnis dan Akuntansi), 20 (1) 2021, 75

Pengaruh Pendidikan, Pengalaman Kerja dan Motivasi Kerja Terhadap Kinerja Karyawan Pada Hotel Champlung Mas Resort \& Spa Legian

\begin{tabular}{|c|c|c|c|c|}
\hline Hasil & $\begin{array}{l}\text { bel } 1 \\
\text { gresi Linear } \mathrm{E} \\
\text { icients }^{\mathrm{a}}\end{array}$ & erganda ${ }^{a}$ & & \\
\hline Variabel & \multicolumn{2}{|c|}{ Koefisien Regresi } & $\mathrm{T}$ & Sig \\
\hline Pendidikan $\left(\mathrm{X}_{1}\right)$ & 0,737 & 0,187 & 3,949 &, 000 \\
\hline Pengalaman $\operatorname{Kerja}\left(\mathrm{X}_{2}\right)$ & 0,353 & 0,155 & 2,271 & 028 \\
\hline Motivasi $\operatorname{Kerja}\left(\mathrm{X}_{3}\right)$ & 0,563 & 0,563 & 4,026 &, 000 \\
\hline (Constant): $-3,271$ & & & & \\
\hline F Statistik: 17,384 & & & & \\
\hline Sig F: 0.000 & & & & \\
\hline $\mathrm{R}^{2}: 0,521$ & & & & \\
\hline $\mathrm{R}: 0,722$ & & & & \\
\hline
\end{tabular}

Sumber: Data diolah

Berdasarkan Tabel 1 dapat ditulis persamaan regresi linear berganda sebagai berikut.

$\mathrm{Y}=-3,271+0,737 \mathrm{X} 1+0,353 \mathrm{X} 2+0,563 \mathrm{X} 3$ Dimana:

$\mathrm{Y}=$ Kinerja iKaryawan

$\mathrm{X} 1=$ Pendidikan

$\mathrm{X} 2=$ Pengalaman iKerja

X3= Motivasi iKerja

Persamaan regresi linear berganda tersebut menunjukkan arah masing-masing variabel bebas terhadap variabel terikatnya. Persamaan regresi linear berganda tersebut dapat diuraikan sebagai berikut:

$\alpha=$ Nilai konstanta sebesar $-3,271$, artinya apabila pendidikan (X1) pengalaman kerja (X2) dan motivasi kerja (X3) sama dengan nol maka Kinerja Karyawan sebesar i-3,271.

$\mathrm{X} 1=+0,737$ menunjukkan bahwa Pendidikan berpengaruh positif terhadap kinerja karyawan pada Hotel Champlung Mas Resort \& Spa Legian, apabila pendidikan tinggi maka kinerja karyawan akan mengalami peningkatan.

$\mathrm{X} 2=+0,353$, menunjukkan bahwa pengalaman kerja berpengaruh positif terhadap kinerja karyawan pada Hotel Champlung Mas Resort \& Spa Legian, apabila pengalaman kerja tinggi maka kinerja karyawan akan mengalami peningkatan.

$\mathrm{X} 3=+0,563$, menunjukkan bahwa motivasi kerja berpengaruh positif terhadap kinerja karyan pada Hotel Champlung Mas Resort \& Spa Legian, apabila motivasi kerjatinggi maka kinerja karyawan akan mengalami peningkatan.

\section{Pengaruh Pendidikan, Pengalaman Kerja dan Motivasi Kerja Terhadap Kinerja Karyawan}

Berdasarkan uji $\mathrm{F}$ (secara simultan) diperoleh $\mathrm{F}_{\text {hitung }}(17,384)>\mathrm{F}_{\text {tabel }}(2,79)$ dengan nilai signifikansi $\mathrm{F}$ adalah $0,000<0,05$, maka $\mathrm{H} 0$ ditolak. Hal ini berarti bahwa variabel pendidikan (X1) pengalaman kerja (X2) dan motivasi kerja (X3) secara simultan berpenaruh signifikan terhadap kinerja karyawan (Y) pada Hotel Champlung Mas Resort \& Spa Legian dengan nilai R2 $=52,1 \%$, yang berarti bahwa sebesar 52,1\% kinerja karyawan pada Hotel Champlung Mas Resort \& Spa Legian dipengaruhi oleh variable pendidikan (X1) pengalaman kerja (X2) dan motivasi kerja (X3) sedangkan sisanya sebesar $47,9 \%$ dipengaruhi oleh variabel lain yang tidak diteliti pada penelitian ini.

\section{Pengaruh Pendidikan Terhadap Kinerja Karyawan}

Berdasarkan hasil analisis data menunjukkan bahwa pengaruh pendidikan terhadap kinerja karyawan diperoleh $t_{\text {hitung }}(3,949)>t_{\text {tabel }}(2,010)$ dengan tingkat signifikansi $0,000<0,05$, sehingga $\mathrm{HO}$ ditolak dan Ha diterima yang berarti bahwa variabel Pendidikan berpengaruh positif signifikan terhadap kinerja karyawan pada Hotel Champlung Mas Resort \& Spa Legian. Koefisien iregresi $\beta 1$ (variabel ipendidikan) sebesar 0,737 , menunjukkan bahwa semakin tinggi pendidikan maka semakin meningkat kinerja karyawan pada Hotel Champlung Mas Resort \& Spa Legian.

\section{Pengaruh Pengalaman Kerja Terhadap Kinerja Karyawan}

Berdasarkan hasil analisis data menunjukkan bahwa pengaruh pengalaman kerja terhadap 
kinerja karyawan diperoleh $t_{\text {hitung }}(2,271)>t_{\text {tabel }}(2,010)$ dengan tingkat signifikansi $0,028<0,05$, sehingga $\mathrm{HO}$ ditolak dan $\mathrm{Ha}$ diterima yang berarti bahwa variabel pengalaman kerja berpengaruh positif signifikan terhadap kinerja karyawan pada Hotel Champlung Mas Resort \& Spa Legian. Koefisien regresi $\beta 2$ (variabel pengalaman kerja) sebesar 0,353 menunjukkan bahwa semakin tinggi pengalaman kerja maka semakin meningkat kinerja karyawan pada Hotel Champlung Mas Resort \& Spa Legian.

\section{Pengaruh Motivasi Kerja Terhadap Kinerja Karyawan}

Berdasarkan hasil analisis data menunjukkan bahwa pengaruh motivasi kerja terhadap kinerja karyawan diperoleh $t_{\text {hitung }}(4,026)>t_{\text {tabel }}(2,010)$ dengan tingkat signifikansi $0,000<0,05$, sehingga $\mathrm{HO}$ ditolak dan Ha diterima yang berarti bahwa ivariabel motivasi kerja berpengaruh positif signifikan terhadap kinerja karyawan pada Hotel Champlung Mas Resort \& Spa Legian. Koefisien regresi $\beta 3$ (variabel motivasi kerja) sebesar 0,563 menunjukkan bahwa semakin tinggi imotivasi kerja maka semakin meningkat kinerja karyawan pada Hotel Champlung Mas Resort \& Spa Legian.

\section{SIMPULAN}

Berdasarkan hasil analisis data dan pembahasan, maka didapat simpulan hasil penelitian sebagai berikut; Pendidikan, Pengalaman Kerja dan Motivasi Kerja berpengaruh positif dan signifikan secara simultan terhadap kinerja karyawan pada Hotel Champlung Mas Resort \& Spa Legian. Pendidikan berpengaruh positif dan signifikan secara parsial terhadap kinerja karyawan pada Hotel Champlung Mas Resort \& Spa Legian. Hal ini berarti bahwa semakin tinggi pendidikan maka semakin meningkatkan kinerja karyawan. Pengalaman kerja berpengaruh positif dan signifikan secara parsial terhadap kinerja karyawan pada Hotel Champlung Mas Resort \& Spa Legian. Hal ini berarti bahwa semakin tinggi pengalaman kerja maka semakin meningkat kinerja karyawan. Motivasi kerja berpengaruh positif dan signifikan secara parsial terhadap kinerja karyawan pada Hotel Champlung Mas Resort \& Spa Legian. Hal ini berarti bahwa semakin tinggi motivasi kerja maka semakin meningkat kinerja karyawan.

\section{DAFTAR PUSTAKA}

Handoko, T. H. (2014). Dasar-dasar Manajemen Produksi dan Operasi : Edisi ke 1. Yogyakarta: BPFE.

Prawirosentono, S., \& Primasari, D. (2017). Manajemen Sumber Daya Manausia Kinerja dan Motivasi Karyawan Membangun Organisasi Kompetitif Era Perdagangan Bebas Dunia. Yogyakarta: BPFE.

Priansa, J. D. (2016). Perencanaan dan Pengembangan Sumber Daya Manusia. Bandung: Alfabeta.

Sendjaja, S. D. (2004). Pengantar Ilmu Komunikasi. Jakarta: Universitas Terbuka.

Syaifudin, A., \& Sagoro, E. M. (2017). Pengaruh Kepribadian, Lingkungan Keluarga Dan Pendidikan Kewirausahaan Terhadap Minat Berwirausaha Mahasiswa Akuntansi. Profita: Kajian Ilmu Akuntansi, 5(8). Retrieved from http://journal.student.uny.ac.id/ojs/index.php/profita/article/ view/9958 